\title{
EL CUERPO DELIRANTE
}

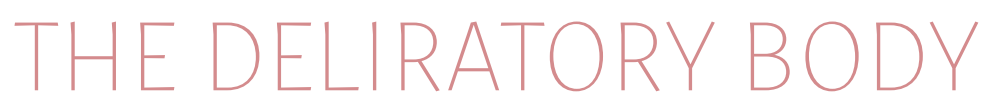

\section{Erika Selene Pérez Vázquez}

http://doi.org/10.37646/huella.v15i15.31

\section{Notas sobre el autor:}

Profesora de la Universidad Autónoma de la Ciudad de México, estudió Filosofía en la UAM; después religión, tanatología, psicoterapia y actualmente realiza el doctorado de Arte. Imparte clases de estética y filosofía del arte. Escribe cuento y poesía.

Remita cualquier duda sobre este artículo al siguiente correo electrónico: selene.perez@uacm.edu.mx

Recibido 21/04/2021 Aceptado: 01/06/2021 


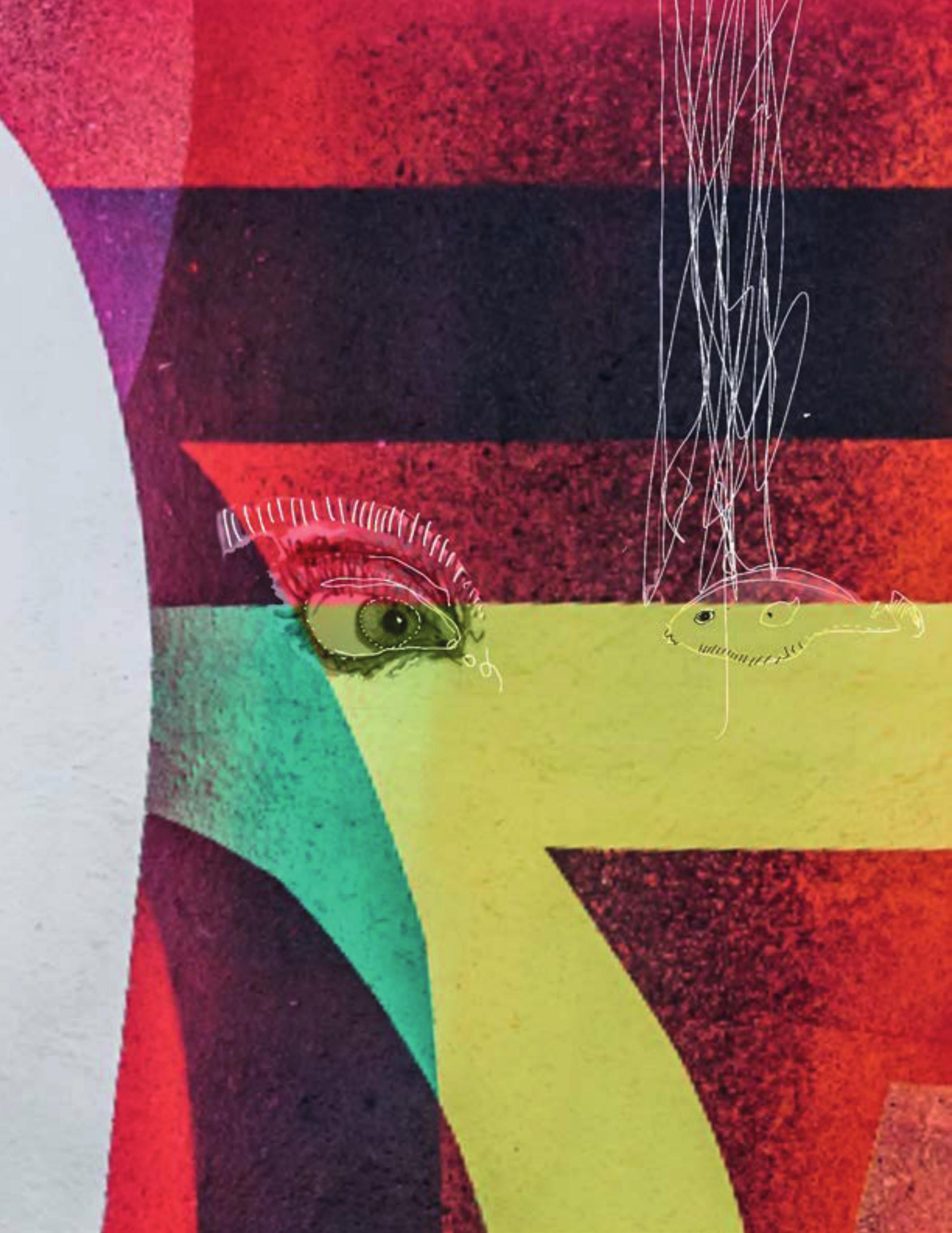




\section{Buscando descubro}

A dónde busco la luz va la mano

miro los párpados y descubro algo

recorro el camino.

Me pinto las uñas de azul claro

e imagino montañas donde alguien viene

-el desconocimiento-.

Susurro algo mientras no hay nadie

-el silencio grita-.

Colecciono plantas

todas ellas crecen

y verdean la mirada

somos bosques por dentro.

Un árbol recorre entonces mi garganta

el azul de mis uñas sigue ahí

nos llenamos de colores mientras alguien nos sueña.

Florecemos en el sueño de alguien más.

Concurrimos en el deseo de otro.

Existimos en la nada que lo habita todo. 


\section{El cuerpo considera no llamar}

Eres picazón y alergia

el síntoma de lo vivo

porque eso brotamos.

Somos palmeras en plena primavera

la luz que nos oscurece de pronto nos dibuja

de la A a la Z ella se nombra en la cavidad del sonido

recojo la palma y encorvo la maña.

Tan extraño es el éxtasis

como piano desafinado.

Dejaré la puerta cerrada

que los humores perfumen los dedos

el árbol de la mano se haga fuerte

la $M$ de la palma signifique algo.

Las venas como ramificación

derecho al corazón

tanta sensibilidad

a perogrullo te llamamos

ayer me enteré de que ya no vives aquí. 


\section{Contener el significado}

¿Dónde están los sentidos?

Si no es en la mirada.

Los presocráticos lo querían en el oído.

Desde el ahí no puedo extraviarte

la musicalidad le llaman naturaleza

te envuelve.

Como nota musical Pitágoras resuelve, sin embargo, yo prefiero tocar desde los párpados para escuchar-te-nos. 


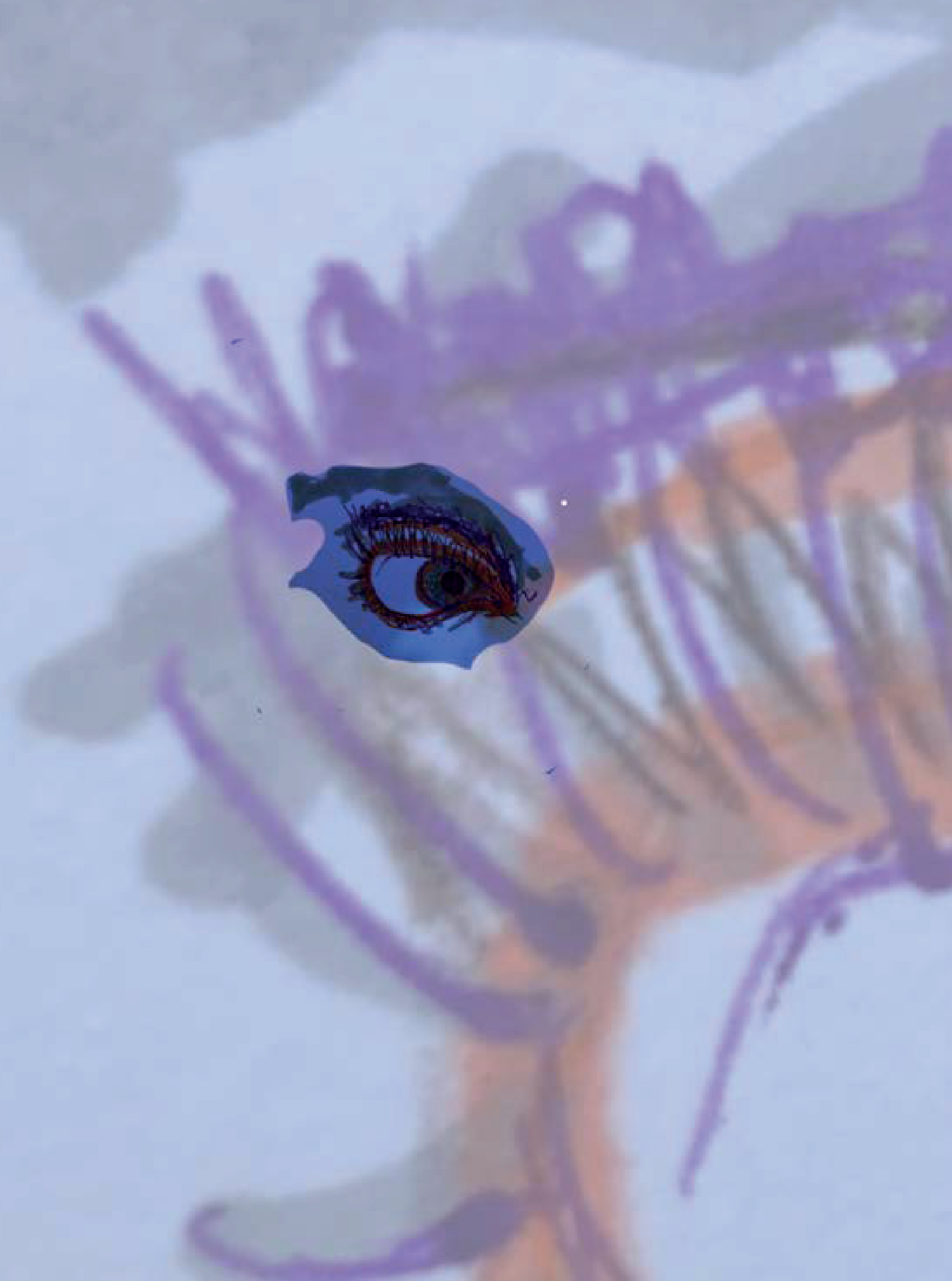

